\title{
Impact of the learning environment on career intentions of paediatric interns
}

\author{
K L Naidoo, ${ }^{1}$ MB ChB, DCH, FC Paed (SA); J M van Wyk, ${ }^{2}$ BSc (Ed), BEd, MEd, PhD; M Adhikari, ${ }^{1,3}$ MB ChB, FCP (Paed) (SA), PhD \\ ${ }^{1}$ Department of Paediatrics and Child Health, School of Clinical Medicine, College of Health Sciences, Nelson R Mandela School of Medicine, \\ University of KwaZulu-Natal, Durban, South Africa \\ ${ }^{2}$ Department of Clinical and Professional Practice, School of Clinical Medicine, College of Health Sciences, Nelson R Mandela School of Medicine, \\ University of KwaZulu-Natal, Durban, South Africa \\ ${ }^{3}$ Postgraduate Office, School of Clinical Medicine, College of Health Sciences, Nelson R Mandela School of Medicine, University of KwaZulu-Natal, \\ Durban, South Africa
}

Corresponding author: K L Naidoo (naidook9@ukzn.ac.za)

\begin{abstract}
Background. High childhood disease burdens in South Africa (SA) prioritise the need for careers in paediatrics. Experiences of junior doctors during internship may influence career trajectories in a direction that is discordant with national health priorities.

Objective. To explore the influence of the learning environment and demography on career intentions of SA paediatric interns.

Methods. This cross-sectional study involved sampling intern groups at the start and completion of internship in paediatrics to determine their career intentions. A validated version of the Postgraduate Hospital Educational Environmental Measure was used to measure perceptions of the learning environment (LE) in the post-paediatric internship cohort. Measures of the LE in combination with demographic factors were compared with career intentions. Associations were determined by $t$-tests or analysis of variance and $\chi^{2}$ tests.

Results. A total sample size of 422 was obtained from two separate cohorts, which were demographically similar except for age. Most interns (88.4\%) intended to remain in SA, with $72.6 \%$ indicating an intention to practise in the public healthcare sector. There was a high intention to specialise (85.9\%), and $60.2 \%$ were keen on a career that involved children. Previous educational exposure and demographic factors other than gender did not significantly influence career intentions. Perceptions of the LE significantly influenced decisions to stay in SA's public sector and to care for children. The decision to specialise, however, was not influenced by demographic variables or perceptions of the LE. Conclusions. Paediatric interns from diverse sociocultural and educational backgrounds had similar career intentions. Most interns were keen to work with children in SA's public sector. However, learning experiences during internship significantly influence these intentions and have the potential to drive young doctors away from SA, its public health service and paediatric care. Ensuring that training and support of interns are optimised is essential if SA is to align its healthcare needs with the aspirations of its future healthcare workers.
\end{abstract}

S Afr Med J 2017;107(11):987-993. DOI:10.7196/SAMJ.2017.v107i11.12589

The mismatch between the number of medical practitioners in the public healthcare sector and disease burden is most evident in sub-Saharan African (SSA) countries. ${ }^{[1,2]}$ Despite efforts to increase the number of medical practitioners, high migration from SSA countries and the shift towards private healthcare have perpetuated this inequity. ${ }^{[3]}$ Newly qualified doctors usually start their careers in the public sector, but the odds of their leaving this sector increases with time. ${ }^{[4]}$ These patterns of career choice highlight the mismatch between the intentions of most African medical students and the health workforce needs of the continent. ${ }^{[3]}$ A similar pattern is evident in the South African (SA) setting, with inequitable doctor-patient ratios between private and public healthcare and rural and urban practice, and high aspirations on the part of junior doctors to work abroad. ${ }^{[5]}$ Within-country trends further indicate the continued preference for private rather than public health service among practitioners. ${ }^{[6]}$

While the undergraduate training period serves as an important influence on career choice, the experience immediately after graduation is becoming increasingly critical in these decisions. ${ }^{[7,8]}$ Career directions seem to be decided early in junior doctors' postgraduate years. ${ }^{[9,10]}$ SA medical doctors enter a 2 -year internship immediately after graduation. This formative period includes four major and four minor disciplines. Paediatrics was introduced as a major discipline concurrent with the implementation of the 2-year internship ${ }^{[11]}$ and is a relatively recent addition to the internship rotation compared with the other major disciplines of surgery, internal medicine and obstetrics. In addition, demographic shifts in the composition of interns have occurred following changes in the recruitment policies of most SA medical schools, in attempts to redress the inequities of apartheid. ${ }^{[12]}$ Little is known about the influence of internship training on career intentions, specifically in terms of paediatrics, in a transforming medical community.

SA paediatric interns work in an environment with a high disease burden. High neonatal, infant and under-five mortality rates reflect multiple burdens of disease, with HIV, tuberculosis and socioeconomic deprivation influencing childhood disease patterns. ${ }^{[13]}$ Excessive workloads, high levels of stress and burnout are constantly being reported among all junior doctors, including interns. ${ }^{[14]}$ In addition, poor supervision and institutional challenges with regard to poor infrastructure and management add further dimensions to an already challenging learning environment (LE) for interns.

The LE has been defined as a 'set of factors that describe a learner's experience within an organization. ${ }^{\text {'15] }}$ The clinical LE has been described as consisting of three parts. ${ }^{[16]}$ The first part includes the provision of shelter, comfort and food, and refers to the infrastructure and physical facilities interns work in. The second part relates to support and feedback and includes the levels of harassment interns experience in the LE. The third part refers to the structured training, supervision, coaching and 
learning required to develop the professional expertise of the intern. ${ }^{[16,17]}$ The LE has been shown to influence trainees' learning processes and outcomes, ${ }^{[18,19]}$ and satisfaction with the LE influences future achievements of trainees. ${ }^{[20,21]}$ The Postgraduate Hospital Educational Environmental Measure (PHEEM) is a well-recognised instrument used internationally to assess the LE in postgraduate medicine, including medical internship. ${ }^{[22,23]}$

Attempts to determine the factors that influence the decisions of medical practitioners to care for children in areas with a high childhood disease burden require an understanding of the experiences and career intentions of interns who are already serving this need. The internship period offers a window of opportunity to influence long-term career choices. ${ }^{[24]}$ To align national health priorities and to optimise healthcare would require identification of strategies to target medical practitioners early in their careers. ${ }^{[3]}$

\section{Objective}

To explore the influence of the LE in internship and demographic factors on the career intentions of interns with regard to paediatrics in an environment with a high disease burden by: (i) exploring the intentions of a cohort of SA medical interns in terms of future careers involving caring for children in the public health system; (ii) comparing career intentions before and after exposure to the paediatric internship LE; and (iii) investigating the influence of demographic factors and perceptions of the LE on interns' career intentions.

\section{Methods \\ Research design}

This was a cross-sectional cohort study.

\section{Procedure}

The sample population included two cohorts of interns sampled at two different times from four hospital complexes (comprising eight hospitals) in both major cities of KwaZulu-Natal (KZN) Province, SA. All four hospital complexes include large regional hospitals with high childhood disease burdens.

The primary cohort consisted of interns who had completed their internship in paediatrics and so had experienced the LE in this domain in an institution with a high disease burden. This cohort was sampled at the end of December 2015 and is referred to as the post-internship cohort. The second cohort, sampled in January 2016, consisted of new interns who were about to start their internship and had not had any exposure to the LE of internship in paediatrics. All eligible interns were informed of the study and invited to participate. Participants were informed of their rights and could withdraw at any stage.

\section{The survey instrument}

The primary author (KLN) used a survey instrument that comprised three segments. This instrument was part of a larger study on learning experiences of interns in KZN. The first segment of the survey instrument collected data on demographic variables related to sociocultural factors and prior educational exposure. Sociocultural variables assessed were gender, self-identified ethnicity, geographical location of the intern's home, and parental educational level. Geographical location was defined as consisting of three categories, namely urban (mainly city and suburban neighbourhoods), semiurban (mainly 'township' neighbourhoods outside the main cities or towns) and rural (growing up on a farm). These distinctly different areas reflect significant racial and socioeconomic divisions in the SA context. ${ }^{[25]}$ Prior educational exposure was determined by gathering data on the type of high school attended (whether a fee-paying or non-fee-paying school) and university attended for undergraduate medical training (whether the local university or a university outside the province or country). ${ }^{[26]}$ These variables are recognised as important criteria in redressing inequity, and most SA medical schools have amended their undergraduate selection criteria based on these factors. ${ }^{[12]}$ Self-reported undergraduate performance in paediatrics in the final year was used as a marker of undergraduate interest in paediatrics and was assessed to determine any relationship with career intention.

The second segment of the instrument collected data relating to perceptions of the LE as measured by the PHEEM. The original developers of the instrument, following qualitative and quantitative methods of research, proposed three subscales related to teaching, role autonomy and social support. ${ }^{[22]}$ A local SA version of the PHEEM instrument was validated in a cohort of paediatric interns in four hospital complexes in Durban and Pietermaritzburg. ${ }^{[26]}$ Cronbach's alpha to assess internal consistency of the local PHEEM was 0.943 for the overall scale. Cronbach's alpha for the teaching, autonomy, and social support subscales was $0.920,0.815$ and 0.760 , indicating good reliability. Construct validity was measured with a factor analysis that indicated that a scale with three factors had $42 \%$ of the total variance explained. The three subscales based on the original tool were used to assess the LE. ${ }^{[26]}$

The PHEEM used in our study had eight minor changes to the original 40 items to accommodate terminology relevant to SA and paediatrics. Each participant scored each item on a five-point Likert scale, where $1=$ strongly disagree and $5=$ strongly agree. The original questionnaire used a scale of 0 - 4 , while we followed a more conventional scale of $1-5$ as used by some authors. ${ }^{[20]}$ The LE was measured only in the post-internship cohort who had completed their internship in paediatrics in December 2015.

The third segment of the survey instrument collected data on career intentions of interns in terms of their long-term future. This included working in or outside SA, and if the decision was to work in SA, whether this would be in the public or the private health sector. Information was also obtained on the intention to enter a medical specialty or general medical practice, and the likelihood of caring for children in whatever future career the respondent intended to pursue.

The questionnaire was group-administered by the primary author at each hospital. The group-administrative procedure ensured an improved response rate and immediate response to queries.

\section{Sample size}

A sample size calculation was based on the comparison of demographic variables and career intentions with PHEEM scores. Using a one-way analysis of variance (ANOVA) with up to four groups, the detection of a medium effect size (Cohen's $d$ ), at $80 \%$ power and the $5 \%$ significance level, a sample size of 180 was required. ${ }^{[27]}$

\section{Data analysis}

The overall PHEEM scale and subscale scores were calculated for each participant. The negatively worded items $(7,8,11$ and 13) were reverse-scored. Where there were missing data, means were computed based on data for available items, provided this did not exceed $20 \%$ of the items. The $\chi^{2}$ test was used to assess the relationships between demographic variables and career intentions, and between these variables and intern group. Fisher's exact test was used for $2 \times 2$ tables or where the requirements for the $\chi^{2}$ test could not be met. The relationship between age, PHEEM scores and demographic variables and career intentions was assessed by the $t$-test (or ANOVA for more than two categories). Where the data did not meet the assumptions of these tests, a non-parametric alternative, the Wilcoxon rank sum test (or the Kruskal-Wallis test for more than two categories) was 
used. Data analysis was carried out using SAS version 9.4 for Windows (SAS Institute, USA). The $5 \%$ significance level was used.

\section{Ethical approval}

Ethical approval for the study was obtained from the University of KwaZulu-Natal Biomedical Research Ethics Committee (ref. no. BE177.15). Permission was also granted by the various institutions, as well as the Health Research and Knowledge Management Subcomponent of the KZN Department of Health (ref no. NHRD:KZ_2015RP30_226).

\section{Results \\ Sample size and response rates}

The total sample size of 422 respondents was adequate for the purposes of the study. The 2015 post-internship cohort $(n=209)$ represented a response rate of $55.3 \%$, and the 2016 pre-internship cohort $(n=213)$ a response rate of $86.9 \%$.

\section{Demographic factors}

As expected, there was a significant age difference $(p<0.0001)$ between the preand post-internship cohorts. The median age of the pre-internship cohort was 24 (interquartile range (IQR) 24 - 25) years, as opposed to the median of 26 (IQR 25 - 27) years for the post-internship cohort.

Table 1 sets out the other demographic characteristics of the two cohorts of interns surveyed. With regard to gender, ethnicity, geographical location of the intern's home, parental educational level, high school attended and self-reported final-year marks in paediatrics, the differences between the cohorts surveyed were not statistically significant. Most of the interns sampled (87.5\%) had completed their undergraduate studies at medical schools in SA, with $12.5 \%$ having graduated from non-SA medical schools. Fig. 1 illustrates the distribution of interns sampled who had attended various SA medical schools. The largest proportion had obtained their undergraduate medical qualification from the University of KwaZulu-Natal (29.4\%), followed by the University of Pretoria (13.8\%), Stellenbosch

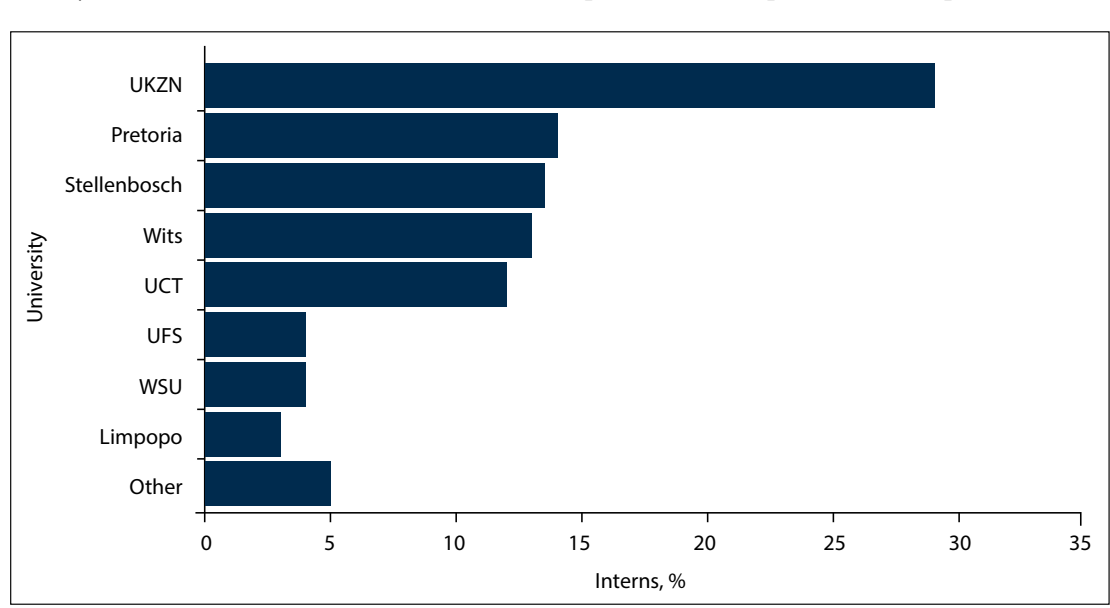

Fig. 1. Distribution of the interns sampled ( $\mathrm{N}=411)$ in respect of South African medical schools attended. (UKZN = University of KwaZulu-Natal; Pretoria $=$ University of Pretoria; Stellenbosch $=$ Stellenbosch University; Wits = University of the Witwatersrand; UCT = University of Cape Town; UFS = University of the Free State; $W S U=$ Walter Sisulu University; Limpopo = University of Limpopo.)

Table 1. Comparison of demographic characteristics of the pre- and post-internship cohorts of interns surveyed

\begin{tabular}{|c|c|c|c|c|}
\hline Category & Overall, $n(\%)$ & Pre-internship, $n$ (\%) & Post-internship, $\boldsymbol{n}$ (\%) & $\begin{array}{l}p \text {-value for between } \\
\text { group test }\end{array}$ \\
\hline Gender $(N=411)$ & & & & 0.072 \\
\hline Male & $166(40.4)$ & $75(35.9)$ & $91(45.1)$ & \\
\hline Female & $245(59.6)$ & $134(64.1)$ & $111(54.9)$ & \\
\hline Ethnicity $(N=392)$ & & & & 0.22 \\
\hline White & $129(32.9)$ & $76(37.6)$ & $53(27.9)$ & \\
\hline Indian & $122(31.1)$ & $58(28.7)$ & $64(33.7)$ & \\
\hline Black African & $114(29.1)$ & $54(26.7)$ & $60(31.5)$ & \\
\hline Coloured & $27(6.9)$ & $14(7.0)$ & $13(6.9)$ & \\
\hline Geographical location $(N=409)$ & & & & 0.31 \\
\hline Urban & $250(61.1)$ & $131(63.3)$ & $119(58.9)$ & \\
\hline Township & $114(27.9)$ & $51(24.6)$ & $63(31.2)$ & \\
\hline Rural & $45(11.0)$ & $25(12.1)$ & $20(9.9)$ & \\
\hline Parental education level $(N=406)$ & & & & 0.26 \\
\hline Non-university & $122(30.0)$ & $57(27.5)$ & $65(32.6)$ & \\
\hline University & $284(70.0)$ & $150(72.5)$ & $134(67.3)$ & \\
\hline High-school type $(N=409)$ & & & & 0.075 \\
\hline Non-fee & $160(39.1)$ & $73(34.9)$ & $87(43.5)$ & \\
\hline Fee paying & $249(60.9)$ & $136(65.1)$ & $113(56.5)$ & \\
\hline Final-year paediatrics mark $(N=404)$ & & & & 0.23 \\
\hline$<60 \%$ & $30(7.4)$ & $11(5.4)$ & $19(9.5)$ & \\
\hline$\geq 60 \%$ & $374(92.5)$ & $192(94.6)$ & $182(90.5)$ & \\
\hline
\end{tabular}


Table 2. Career intentions of the pre- and post-internship cohorts

\begin{tabular}{|c|c|c|c|c|}
\hline Category & $\begin{array}{l}\text { Overall }(N=422), \\
n(\%)\end{array}$ & $\begin{array}{l}\text { Pre-internship ( } N=213), \\
n(\%)\end{array}$ & $\begin{array}{l}\text { Post-internship } \\
(N=209), n(\%)\end{array}$ & $\begin{array}{l}p \text {-value for between- } \\
\text { group test }\end{array}$ \\
\hline Stay in SA & $343(88.4)$ & $178(94.0)$ & $165(87.3)$ & \multirow{2}{*}{0.51} \\
\hline Leave SA & $45(11.6)$ & $21(10.6)$ & $24(12.7)$ & \\
\hline Private sector & $94(27.4)$ & $40(22.5)$ & $54(32.7)$ & \multirow{2}{*}{$0.03^{*}$} \\
\hline Public sector & $249(72.6)$ & $138(77.5)$ & $111(67.3)$ & \\
\hline Will care for children & $248(60.2)$ & $128(61.8)$ & $120(58.5)$ & \multirow{2}{*}{0.49} \\
\hline Prefer not to care for children & $164(39.8)$ & $793(38.2)$ & $85(41.5)$ & \\
\hline Specialise & $354(85.9)$ & $176(85)$ & $178(86.8)$ & \multirow{2}{*}{0.13} \\
\hline General practice & $50(12.3)$ & $31(14.9)$ & $19(9.6)$ & \\
\hline $\begin{array}{l}S A=\text { South Africa. } \\
{ }^{*} \text { Significant at } p<0.05 .\end{array}$ & & & & \\
\hline
\end{tabular}

was a percentage significantly higher than the $22.5 \%$ reported in the pre-internship cohort who indicated a preference for private sector practice.

\section{Intention to care for children and intention to specialise} When asked about the likelihood of caring for children in their future careers (whether in general practice or in their chosen specialty), $60.2 \%$ intended to care for children. This percentage was similar across the cohorts. The majority of interns $(85.9 \%)$ intended to specialise in the future. This figure was not significantly different in the two cohorts sampled.

\section{Influence of demographic and educational factors on career intentions}

Table 3 shows the relationships between demographic variables and previous educational exposure with career intentions of the interns.

Ethnicity, family educational level, geographical location of the intern's home and type of high school attended did not significantly influence intentions to practise in SA or or to practise in the public or private sectors. These sociocultural factors were also not found to be significant in influencing intentions to specialise among the sampled interns.

Significant associations were found between gender and intentions to practice in the private sector and to care for children. A higher proportion of male interns ( $44.4 \%$ of all male interns) than female interns ( $16.6 \%$ of all female interns) indicated an intention to move to the private sector. A higher proportion of female interns (64.4\% of all female interns) than male interns (only $45.3 \%$ ) indicated an intention to care for children in the future. Significant associations were found between ethnicity, the geographical location of the intern's home and their intention to care for children. More interns who self-identified as black African (71.7\%) indicated a preference for paediatric service compared with Indian (60.0\%) and white (54.3\%) interns and those of mixed race $(40.7 \%)$. A higher proportion of interns from rural areas $(82.2 \%)$ than interns from urban $(58.0 \%)$ and semi-urban (57.0\%) locations intended to care for children.

\section{Educational factors and career intentions}

The intentions of interns to practise in SA, to specialise and to work with children were not significantly associated with the medical school they graduated from or their performance in the final year of their undergraduate paediatric studies.

An intention to stay in the public sector in their future careers (among those who indicated that they intended to practise in SA) was significantly associated with whether an intern had graduated in SA or in another country, and with performance in the final year of undergraduate paediatric studies. A higher proportion of non-SAgraduated interns (44.7\%) than locally graduated interns (25.3\%) indicated an intention to work in the private sector.

Compared with interns who indicated that they had obtained $\geq 60 \%$ in final-year paediatrics, a higher proportion of interns who had scored $<60 \%$ indicated a preference to work in the private sector (23.9\% v. $44.0 \%)$.

\section{Association between perceptions of the LE} and career intentions

The relationship between the overall PHEEM scores and the three subscale scores measuring interns' perception of their LE and career intentions is summarised in Table 4.

Significant associations were found between the overall PHEEM score and career intentions of interns following the paediatric internship. There was a significant association between the mean PHEEM score and intention to practise in SA. The mean score (standard deviation (SD)) for interns intending to leave SA (3.07 (0.65)) was significantly lower than that for interns intending to practise in the SA private sector $(3.50(0.54))$ and in the SA public sector (3.62 (0.43)) (Fig. 2). Similar relationships were seen across all three of the PHEEM subscales of teaching, role autonomy and social support. There was a significant relationship between the overall PHEEM score and intention to pursue paediatric practice in the future. Interns who indicated an intention to care for children scored significantly higher on the PHEEM (3.59 (0.44)) than those who

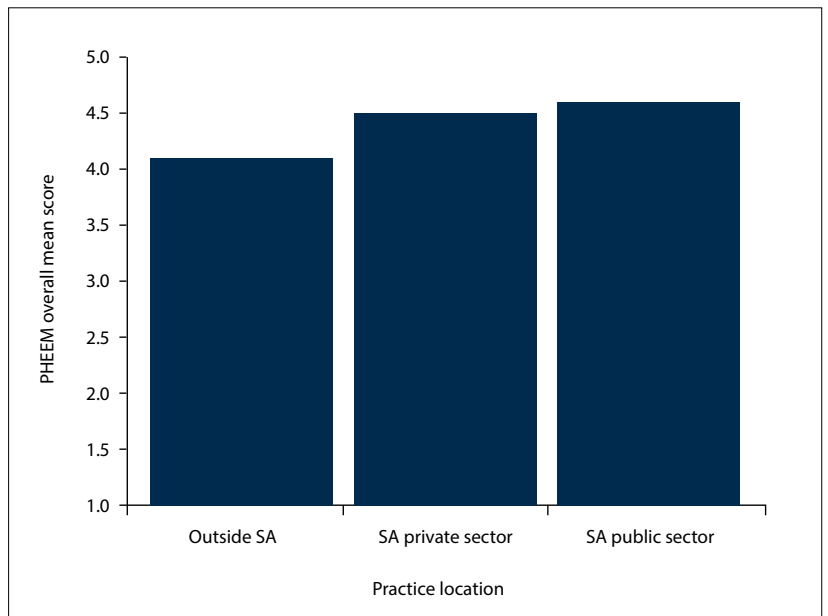

Fig. 2. Association between PHEEM score and intention to practise in $S A$, and in the private or the public sector. (SA = South Africa; PHEEM = Postgraduate Hospital Educational Environmental Measure.) 
Table 3. Relationship between demographic variables and prior educational experience with career intentions

\begin{tabular}{|c|c|c|c|c|c|c|c|c|}
\hline \multirow[b]{2}{*}{ Category } & \multicolumn{4}{|c|}{ Area of practice } & \multicolumn{2}{|c|}{$\begin{array}{l}\text { Intention to care } \\
\text { for children }\end{array}$} & \multicolumn{2}{|c|}{ Intention to specialise } \\
\hline & Stay in SA & Leave SA & $\begin{array}{l}\text { Private } \\
\text { sector }\end{array}$ & $\begin{array}{l}\text { Public } \\
\text { sector }\end{array}$ & $\begin{array}{l}\text { Will care } \\
\text { for children }\end{array}$ & $\begin{array}{l}\text { Prefer not to } \\
\text { care for children }\end{array}$ & Specialise & $\begin{array}{l}\text { General } \\
\text { practice }\end{array}$ \\
\hline \multicolumn{9}{|l|}{ Gender } \\
\hline Male & 88.2 & 11.8 & 44.5 & 55.6 & 45.3 & 54.7 & 86.5 & 13.5 \\
\hline Female & 89.5 & 10.5 & 16.6 & 83.4 & 64.4 & 35.6 & 13.5 & 87.3 \\
\hline Total, \% (n) & $89.0(340)$ & $11.0(42)$ & $27.7(94)$ & $72.3(246)$ & $60.5(245)$ & $39.5(160)$ & $86.9(341)$ & $13.1(51)$ \\
\hline$p$-value & \multicolumn{2}{|c|}{0.69} & \multicolumn{2}{|c|}{$<0.0001^{*}$} & \multicolumn{2}{|c|}{$<0.05^{*}$} & \multicolumn{2}{|c|}{0.81} \\
\hline \multicolumn{9}{|l|}{ Ethnicity } \\
\hline Black African & 91.5 & 8.4 & 28.5 & 71.4 & 71.7 & 28.3 & 90.5 & 9.4 \\
\hline Mixed race & 88.5 & 11.5 & 17.4 & 82.6 & 40.7 & 59.3 & 86.9 & 23.1 \\
\hline Indian & 88.8 & 11.2 & 21.4 & 78.6 & 60.0 & 40.0 & 89.8 & 10.2 \\
\hline White & 89.7 & 10.3 & 35.2 & 64.8 & 54.3 & 45.7 & 82.4 & 17.6 \\
\hline Total, \% $(n)$ & $89.9(329)$ & $10.1(37)$ & $27.7(91)$ & $72.3(238)$ & $60.2(233)$ & $39.8(154)$ & $86.7(325)$ & $13.3(50)$ \\
\hline$p$-value & \multicolumn{2}{|c|}{0.91} & \multicolumn{2}{|c|}{0.09} & \multicolumn{2}{|c|}{$0.006^{*}$} & \multicolumn{2}{|c|}{0.08} \\
\hline \multicolumn{9}{|c|}{ Parental education level } \\
\hline University & 89.7 & 10.3 & 29.1 & 70.9 & 60.3 & 39.7 & 88.9 & 11.1 \\
\hline Non-university & 87.2 & 12.8 & 23.5 & 76.5 & 62.1 & 37.9 & 83.9 & 16.1 \\
\hline Total, \% (n) & $88.9(336)$ & $11.1(42)$ & $27.4(92)$ & $72.6(244)$ & $60.8(244)$ & $39.2(157)$ & $87.4(334)$ & $12.6(49)$ \\
\hline$p$-value & \multicolumn{2}{|c|}{0.48} & \multicolumn{2}{|c|}{0.29} & \multicolumn{2}{|c|}{0.72} & \multicolumn{2}{|c|}{0.17} \\
\hline \multicolumn{9}{|c|}{ Geographical location } \\
\hline Urban & 87.9 & 12.2 & 27.1 & 72.9 & 58.0 & 42.0 & 86.2 & 13.8 \\
\hline Semi-urban & 88.6 & 11.4 & 30.1 & 69.9 & 57.0 & 43.0 & 87.5 & 12.5 \\
\hline Rural & 95.6 & 4.4 & 25.6 & 74.4 & 82.2 & 17.8 & 90 & 10.0 \\
\hline Total, \% (n) & 89.0 & 11.0 & $27.7(94)$ & $72.3(245)$ & $60.4(244)$ & $39.6(160)$ & $87(340)$ & $13.0(51)$ \\
\hline$p$-value & \multicolumn{2}{|c|}{0.32} & \multicolumn{2}{|c|}{0.82} & \multicolumn{2}{|c|}{$0.006^{*}$} & \multicolumn{2}{|c|}{0.787} \\
\hline \multicolumn{9}{|l|}{ High school type } \\
\hline Fee paying & 84.2 & 15.8 & 30.1 & 69.9 & 59.4 & 40.6 & 87.2 & 12.8 \\
\hline Non-fee & 89.3 & 10.7 & 23.9 & 76.1 & 62.0 & 38.0 & 86.8 & 13.2 \\
\hline Total, \% (n) & $86.6(278)$ & $13.4(43)$ & $27.6(94)$ & $72.4(246)$ & $60.4(246)$ & $39.6(161)$ & 87.1 & $12.9(51)$ \\
\hline$p$-value & & 18 & & 21 & & 6 & & .92 \\
\hline $\begin{array}{l}\text { Where undergradu } \\
\text { studies done }\end{array}$ & & & & & & & & \\
\hline SA & 85.8 & 14.2 & 25.3 & 74.7 & 59.2 & 40.8 & 86.5 & 13.5 \\
\hline Non-SA & 88.0 & 12.0 & 44.7 & 55.3 & 71.4 & 28.6 & 92.0 & 8.0 \\
\hline Total, \% (n) & $86.1(261)$ & $13.9(42)$ & $32.7(93)$ & $86.3(245)$ & $60.6(245)$ & 39.4 & $87.2(342)$ & $12.8(50)$ \\
\hline$p$-value & & 69 & & $1^{*}$ & & 99 & & .28 \\
\hline $\begin{array}{l}\text { Final-year paediatr } \\
\text { mark }\end{array}$ & & & & & & & & \\
\hline$\geq 60 \%$ & 90.8 & 9.2 & 23.9 & 76.1 & 58.5 & 41.5 & 87.4 & 12.6 \\
\hline$<60 \%$ & 96.1 & 3.9 & 44.0 & 66.0 & 66.7 & 33.0 & 83.4 & 16.6 \\
\hline Total, \% $(n)$ & $91.2(332)$ & $8.8(32)$ & $25.5(82)$ & $74.5(240)$ & $59.1(230)$ & 40.9 (159) & $87.1(337)$ & $12.9(50)$ \\
\hline$p$-value & & 35 & & $26^{*}$ & & 38 & & .52 \\
\hline
\end{tabular}

preferred not to care for children (3.42 (0.56)). A similar relationship was found in the teaching and role autonomy subscales. There was no significant relationship between the intention to specialise and perceptions of the LE as measured by the PHEEM instrument.

\section{Discussion}

This study has shown that perceptions of the LE in which interns work significantly affect their career intentions, while most of the demographic factors analysed were not found to influence these intentions.

The good responses obtained with the group administration are similar to other studies in which the PHEEM was used to measure the LE. ${ }^{[23,28]}$ Apart from the expected age difference, the demographic similiarities between the pre- and post-internship cohorts allowed for the comparison of career intentions across the groups as representing either interns with experience in the paediatric LE during internship or those without experience.

The demographic composition of the interns in these cohorts reflected changes in undergraduate recruitment and admission policies. This sample included an increasing number of black African and female newly qualified doctors in both cohorts, which reflects the overall changes in the medical practitioner community in SA. Although the majority of interns came from urban homes with 
Table 4. PHEEM scores v. career intentions of paediatric interns

\begin{tabular}{|c|c|c|c|c|c|c|c|c|}
\hline \multirow[b]{2}{*}{ Category } & \multicolumn{2}{|r|}{ Overall } & \multicolumn{2}{|c|}{ Teaching subscale } & \multicolumn{2}{|c|}{ Role autonomy subscale } & \multicolumn{2}{|c|}{ Social support } \\
\hline & $n$ & Mean (SD) & $n$ & Mean (SD) & $n$ & Mean (SD) & $n$ & Mean (SD) \\
\hline \multicolumn{9}{|l|}{ Area of practice } \\
\hline Leave SA & 24 & $3.07(0.65)$ & 24 & $3.12(0.79)$ & 20 & $3.26(0.54)$ & 22 & $2.82(0.59)$ \\
\hline SA private sector & 53 & $3.50(0.54)$ & 53 & $3.54(0.65)$ & 53 & $3.60(0.51)$ & 54 & $3.31(0.52)$ \\
\hline SA public sector & 109 & $3.62(0.43)$ & 110 & $3.67(0.51)$ & 105 & $3.74(0.42$ & 109 & $3.4(0.51)$ \\
\hline$p$-value & & $<0.0001^{\star}$ & & $0.0002^{*}$ & & $0.0003^{*}$ & & $<0.0001^{*}$ \\
\hline \multicolumn{9}{|l|}{ Intention to care for children } \\
\hline Will care for children & 117 & $3.59(0.44)$ & 118 & $3.66(0.50)$ & 111 & $3.73(0.42)$ & 118 & $3.36(0.52)$ \\
\hline $\begin{array}{l}\text { Prefer not to care for } \\
\text { children }\end{array}$ & 85 & $3.42(0.56)$ & 85 & $3.46(0.67)$ & 83 & $3.52(0.51)$ & 84 & $3.23(0.56)$ \\
\hline$p$-value & & $0.016^{*}$ & & $0.02^{*}$ & & $0.0019^{*}$ & & 0.098 \\
\hline \multicolumn{9}{|l|}{ Intention to specialise } \\
\hline Prefer to specialise & 175 & $3.51(0.52)$ & 176 & $3.57(0.60)$ & 168 & $3.64(0.48)$ & 176 & $3.30(0.54)$ \\
\hline Prefer general practice & 19 & $3.45(0.40)$ & 19 & $3.51(0.46)$ & 18 & $3.51(0.46)$ & 18 & $3.19(0.41)$ \\
\hline$p$-value & & 0.60 & & 0.64 & & 0.83 & & 0.41 \\
\hline
\end{tabular}

university-educated parents, over a third came from semi-urban or rural homes and nearly a third from families in which neither of the parents had obtained a tertiary qualification.

\section{Practice preference for SA's public sector service}

In this study, only $11.6 \%$ of the interns indicated an intention to leave SA after completion of their internship and community service. This figure is similar to reports from previous SA studies. ${ }^{[5,29]}$ The proportion of medical practitioners intending to emigrate is much higher among cohorts sampled in other SSA countries, reflecting an advantage for SA, possibly owing to its relatively better-resourced postgraduate training infrastructure than other SSA countries. ${ }^{[3,4]}$ This positive trend of the bulk of junior doctors intending to remain in SA provides an opportunity to harness their potential and align it to national priorities. A further positive finding was that over two-thirds $(67.3-77.5 \%)$ of interns intended to work in the public sector. However, the proportion of respondents who intended to work in the public sector dropped after internship, possibly reflecting the influence of the LE on the decision to move from SA's public to private healthcare sector. The trend towards leaving the public sector for the private sector mirrors findings in the rest of SSA ${ }^{[4]}$ where the odds of doing so increase each year. The figures also support those in a study where a third of junior doctors indicated a preference to practise in the private healthcare sector. ${ }^{[3]}$

The finding that ethnicity, family educational background and geographical location of an intern's home had no significant role in decisions to leave SA or to work in the public sector indicates that most newly qualified SA doctors have very similar career intentions. Career intentions seem similiar across universities in SA, and in this study, individual self-reported undergraduate performance was shown not to have any association with career choice. The preference of non-SA-trained graduates to work in the private health sector needs further exploration with larger samples. It is possible that graduates who trained eslewhere are keen to work in SA specifically so that they can enter the lucrative private sector.

\section{Intention to specialise}

The high proportion of respondents intending to specialise in a branch of medicine $(>85 \%)$ is similar to other reports on career choice among junior doctors. ${ }^{[3,5,30]}$ It is diffcult to determine when this decision is actually being made. The high intention to specialise in both the pre- and post-internship cohorts suggests that undergraduates may nurture the idea of specialising, and the internship period, with its modular approach of four major and four minor specialties, serves to entrench the idea further. Demographic factors were not shown to influence the decision to specialise, reinforcing the finding that aspirations were similar among most qualifying interns.

The high proportion of respondents intending to specialise raises concern, especially in view of the fact that national priorities strive to create a strong primary healthcare infrastructure and workforce. Findings that over half of all doctors in developed countries will become general practitioners reflect this discrepancy between junior doctor career intentions and national requirements. ${ }^{[31]}$ Long-term studies have indicated that half of those who intended to specialise were in fact working in general practice when tracked within 10 years after qualification. ${ }^{[9]}$ These findings may suggest that the aspirations to specialise that are firmly entrenched following medical school and internship are incongruent with the actual healthcare needs of most countries. The observation that most medical doctors who originally intended to specialise enter general practice needs further exploration in the SA context, where a strong primary healthcare foundation is integral to national plans to ensure more equitable healthcare delivery.

\section{Intention to care for children}

With the burden of child health remaining high in SA, a major strategy towards improving paediatric care is to ensure the training of healthcare workers who are competent in and passionate about caring for children. Our finding that $\sim 60 \%$ of interns intended to care for children represents another opportunity to harness these desires in the early post-qualification years by mentoring, supporting and encouraging careers in paediatrics and child health during this period. Gender has been recognised as a factor in choosing paediatric care, and this study supports this finding. ${ }^{[32,33]}$ The finding that higher proportions of black Africans and interns from rural areas favoured careers in which they would care for children needs further exploration, especially in the context of the transforming demographics in the medical practioner population.

\section{Influence of the LE on career intentions}

The significant influence of interns' perceptions of the LE on decisions to work in SA, in the public sector and with children clearly indicates the importance of the internship LE in shaping 
career intentions. With the teaching subscale scores in the PHEEM showing signifcant influences on career intentions of respondents who had completed their internship in paediatrics, it is evident that the role of supervisors and the quality of mentoring and training in this environment highly influence career intentions of junior doctors.

This study further indicates that negative influences in the LE steer interns away from careers that would support national health priorities such as caring for children in the public sector. Given the reported challenges in ensuring quality training and optimal standards of care at institutions where interns work, the importance of the internship accreditation processes needs to be re-emphasised to ensure successful learning in an optimal LE. ${ }^{[34-36]}$ Ensuring an optimal LE in internship has the potential to significantly affect longterm health workforce planning.

\section{Study limitations}

This study analysed data from two separate cohorts, as opposed to documenting the changing intentions in one cohort over time. Interns in only one province of SA were sampled, representing the LE of only one provincial health department. Furthermore, the study focused on one specific discipline during internship and may not be representative of other specialties. No qualitative data were collected, and only quantitative measures of self-reported intern perceptions are presented.

\section{Conclusion}

In this study, most newly qualified medical doctors indicated an intention to work in SA's public healthcare sector and a desire to care for children. Apart from gender, other demographic factors did not appear to influence these decisions significantly. However, internship was shown to be a critical phase, as perceptions of the LE signficantly influenced interns' career decisions, with negative experiences potentially steering them away from working with children in SA's public health system. The study shows that the impact of the LE must be considered when designing and accrediting training programmes for junior doctors.

To tackle SA's high childhood disease burden, increased efforts to understand and improve the training environment during paediatric internship are required. Further qualitative studies and investigations across more disciplines and provincial settings are needed to fully understand the roles of factors in training and the LE on future workforce predictions and career trajectories. This brief but critical period in junior doctors' training may be the only opportunity we have to align the aspirations of newly qualified medical practitioners with national healthcare needs.

Acknowledgements. The authors thank Dr Petra Gaylard for assistance with the statistical analysis and Mrs Leora Sewnarain with typing and formatting.

Author contributions. KLN was responsible for study design, data collection, data analysis and drafting the manuscript; JVW was responsible for supervision of the entire work, study design and manuscript review; and MA was responsible for supervision of the entire work and manuscript review. Funding. This publication was made possible by the Medical Education Program International Partnership Initiative (grant no. R24TW008863) from the Office of the United States Global AIDS Coordinator and the US Department of Health and Human Services (National Institutes of Health Office of AIDS Research and Office of Research on Women's Health). Its contents are solely the responsibility of the authors and do not necessarily represent the official views of the US government.

Conflicts of interest. None.
1. World Health Organization. Transformative scale up of health professional education: An effort to increase the numbers of health professionals and to strengthen their impact on population health. March 2011. http://www.who.int/hrh/resources/transformative_education/en/ (accessed 10 April 2017).

2. Frenk J, Chen L, Bhutta Z, et al. Health professionals for a new century: Transforming education to strengthen health systems in an interdependent world. Lancet 2010;376(9756):1923-1958. https://doi org/10.1016/s0140-6736(10)61854-5

3. Burch VC, McKinley D, van Wyk J, et al. Career intentions of medical students trained in six sub-Saharan African countries. Educ Health (Abingdon) 2011;24(3):614. http://www.educationforhealth.net/text. asp?2011/24/3/614/101416 (accessed 5 October 2017).

4. Mandeville K, Ulaya G, Lagarde M, et al. Early career retention of Malawian medical graduates: De Vries E, Irlam J, Couper I, Kornik S. Career plans of final-year medical students in South Africa. S Afr Med J 2010;100(4):227-228. https://doi.org/10.7196/SAMJ.3856

6. Ashmore I. 'Going private': A qualitative comparison of medical specialists' job satisfaction in the public Ashmore J. 'Going private': A qualitative comparison of medical specialists' job satisfaction in the public
and private sectors of South Africa. Hum Resour Health 2013;11:1. https://doi.org/10.1186/1478-4491$11-1$

7. Maisonneuve J, Lambert T, Goldacre M. Doctors' views about training and future careers expressed one year after graduation by UK-trained doctors: Questionnaire surveys undertaken in 2009 and 2010. BMC Med Educ 2014;14:270. https://doi.org/10.1186/s12909-014-0270-5

8. Woolf K, Elton C, Newport M. The specialty choices of graduates from Brighton and Sussex Medical School: A longitudinal cohort study. BMC Med Educ 2015;15:46. https://doi.org/10.1186/s12909-0150328-z

9. Goldacre M, Laxton L, Lambert T. Medical graduates' early career choices of specialty and thei eventual specialty destinations: UK prospective cohort studies. BMJ 2010;341:c3199-c3199. https://doi. org/10.1136/bmj.c3199

10. Al-Shaheen A, Al-Foraih N. Career choices of interns in Kuwait: Influential factors and the impact of the pre-registration year. Med Educ 2014;48(suppl 2):18.

1. Nkabinde T, Ross A, Reid S, Nkwanyana N. Internship training adequately prepares South African medical graduates for community service - with exceptions. S Afr Med J 2013;103(12):930-934. https:// doi.org/10.7196/SAMJ.6702

12. Van der Merwe L, van Zyl G, St Clair Gibson A, et al. South African medical schools: Current state of selection criteria and medical students' demographic profile. S Afr Med J 2015;106(1):76-81. https://doi. org/10.7196/SAMJ.2016.v106i1.9913

13. Pattinson RC. MRC Report. Saving Babies 2010 - 2011: Eighth Report on Perinatal Care in South Africa, Pretoria: Tshepesa Press, 2013. http://www.ppip.co.za/wp-content/uploads/Saving-Babies-2010-2011.pd (accessed 10 April 2017).

14. Rossouw L, Seedat S, Emsley R, Suliman S, Hagemeister D. The prevalence of burnout and depression in medical doctors working in the Cape Town Metropolitan Municipality community healthcare clinics and district hospitals of the provincial government of the Western Cape: A cross-sectional study. S Afr Fam district hospitals of the provincial government of the Western Cape: A cros
Pract 2013;55(6):567-573. https://doi.org/10.1080/20786204.2013.10874418

15. Wall D, Clapham M, Riquelme A, et al. Is PHEEM a multi-dimensional instrument? An international Wall D, Clapham M, Riquelme A, et al. Is PHEEM a multi-dimensional instrument? An intent
perspective. Med Teach 2009;31(11):e521-e527. https://doi.org/10.3109/01421590903095528

perspective. Med Teach 2009;31 (11):e521-e527. https://doi.org/10.3109/01421590903095528
16. Mohanna K, Cottrell E, Wall D, Chambers R. Educational concepts: the theory behind the practical aspects of teaching and learning. In: Teaching Made Easy: A Manual for Health Professionals. 3rd ed.
and aspects of teaching and learning. In: Teach
Boca Raton, Fla: CRC Press, 2010:45-58.

17. Schönrock-Adema J, Heijne-Penninga $M$, van Hell E, Cohen-Schotanus J. Necessary steps in factor Schonrock-Adema J, Heijne-Penninga M, van Hell E, Cohen-Schotanus J. Necessary steps in factor
analysis: Enhancing validation studies of educational instruments: The PHEEM applied to clerks as an analysis: Enhancing validation studies of educational instruments: The PHEEM applied
example. Med Teach 2009;31(6):e226-e232. https://doi.org/10.1080/01421590802516756

example. Med Teach 2009;31(6):e226-e232. https://doi.org/ $10.1080 / 01421590802516756$
18. Hutchinson L. ABC of learning and teaching: Educational environment. BMJ 2003;326(7393):810-812 Hutchinson L. ABC of learning and teaching: $\mathrm{E}$
https://doi.org/810. 10.1136/bmj.326.7393.810

https://doi.org/810. 10.1136/bmj.326.7393.810
19. Könings K, Brand-Gruwel S, Merriënboer J. Towards more powerful learning environments through Könings K, Brand-Gruwel S, Merriënboer J. Towards more powerful learning environments through
combining the perspectives of designers, teachers, and students. Br J Educ Psychol 2005;75(4):645-660. https://doi.org/10.1348/000709905x43616

20. Boor K, Scheele F, van der Vleuten C, Scherpbier A, Teunissen P, Sijtsma K. Psychometric properties of an instrument to measure the clinical learning environment. Med Educ 2007;41(1):92-99. https://doi org/10.1111/j.1365-2929.2006.02651.x

21. Kinoshita K, Tsugawa Y, Barnett PB, Tokuda Y. Challenging cases of professionalism in Japan: Improvement in understanding of professional behaviors among Japanese residents between 2005 and 2013. BMC Med Educ 2015;15:42. https://doi.org/10.1186/s12909-015-0313-6

22. Roff S, McAleer S, Skinner A. Development and validation of an instrument to measure the postgraduate clinical learning and teaching educational environment for hospital-based junior doctors in the UK. Med Teach 2005;27(4):326-331. https://doi.org/10.1080/01421590500150874

23. SoemantriD, Herrera C, Riquelme A. Measuring the educational environment in health professions studies A systematic review. Med Teach 2010;32(12):947-952. https://doi.org/10.3109/01421591003686229

24. Stagg P, Greenhill J, Worley PS. A new model to understand the career choice and practice location decisions of medical graduates. Rural Remote Health 2009:9:1245. http://www.rrh.org.au/articles/ subviewnew.asp?ArticleID=1245 (accessed 26 September 2017)

25. Statistics South Africa. Census 2011. Statistical release 30 October 2012. http://www.statssa.gov.za/ publications/P03014/P030142011.pdf (accessed 10 April 2017).

26. Naidoo KL, van Wyk JM, Adhikari M. 'Sense of belonging': The role of individual factors in the learning environment of South Africa's interns. Afr J Health Prof Educ 2017 (in press).

27. Faul F, Erdfelder E, Lang A, Buchner A. G*Power 3: A flexible statistical power analysis program for the social, behavioral, and biomedical sciences. Behav Res Methods 2007;39(2):175-191. https://doi.
then the social, behavioral, and
org $/ 10.3758 / \mathrm{bf} 03193146$

28. Flaherty G, Connolly R, O'Brien T. Measurement of the postgraduate educational environment of junior doctors training in medicine at an Irish university teaching hospital. Ir J Med Sci 2015;185(3):565-571. doctors training in medicine at an Irish univer

29. Dambisya Y. Career intentions of UNITRA medical students and their perceptions about the future. Educ Health (Abingdon) 2003;16(3):286-297. https://doi.org/10.1080/13576280310001607442

30. Lefevre J, Roupret M, Kerneis S, Karila L. Career choices of medical students: A national survey of 1780 students. Med Educ 2010;44(6):603-612. https://doi.org/10.1111/j.1365-2923.2010.03707.x

31. Lambert T, Goldacre M. Trends in doctors' early career choices for general practice in the UK: Longitudinal questionnaire surveys. Br J Gen Pract 2011;61(588):397-403. https://doi.org/10.3399/ bjgp11 5583173

2. Ochsmann EB. Thinking about giving up clinical practice? A gender-stratified approach to understanding junior doctors' choices. Acad Med 2012;87(1):91-97. https://doi.org/10.1097/acm.0b013e31823aba03

3. Spector N, Cull W, Daniels S, et al. Gender and generational influences on the pediatric workforce an practice. Pediatrics 2014;133(6):1112-1121. https://doi.org/10.1542/peds.2013-3016

34. Sein NN, Tumbo J. Determinants of effective medical intern training at a training hospital in North West Province, South Africa. Afr J Health Prof Educ 2012;4(1):10-14. https://doi.org/10.7196/AJHPE.100

35. Ibeziako O, Chabikuli O, Olorunju S. Hospital reform and staff morale in South Africa: A case study of Dr Yusuf Dadoo Hospital. S Afr Fam Pract 2013;55(2):180-185. https://doi.org/10.1080/20786204.2 013.10874330

36. Bola S, Trollip E, Parkinson F. The state of South African internships: A national survey against HPCSA guidelines. S Afr Med J 2015;105(7):535-539. https://doi.org/10.7196/SAMJnew.7923 